\title{
Game on! Burning issues in game localisation
}

Carme Mangiron $\bowtie$

Universitat Autònoma de Barcelona

Citation: Mangiron, C. (2018). Game on! Burning issues in game localisation. Journal of Audiovisual Translation, 1(1), 122-138.

Editor: A. Jankowska \& J. Pedersen

Received: January 22, 2018

Accepted: June 30, 2018

Published: November 15, 2018

Funding: Catalan Government funds 2017SGR113.

Copyright: (C2018 Mangiron. This is an open access article distributed under the terms of the Creative Commons Attribution License. This allows for unrestricted use, distribution, and reproduction in any medium, provided the original author and source are credited.

\section{Abstract}

Game localisation is a type of audiovisual translation that has gradually been gathering scholarly attention since the mid-2000s, mainly due to the increasing and ubiquitous presence of video games in the digital society and the gaming industry's need to localise content in order to access global markets. This paper will focus on burning issues in this field, that is, issues that require specific attention, from an industry and/or an academic perspective. These include the position of game localisation within the wider translation studies framework, the relationship between game localisation and audiovisual translation, game accessibility, reception studies, translation quality, collaborative translation, technology, and translator training.

Key words: video games, game localisation, audiovisual translation (AVT), game accessibility, reception studies, quality, collaborative translation, technology, translator training

凶carme.mangiron@uab.cat; https://orcid.org/0000-0002-6421-8581 


\section{Introduction}

Over the last four decades, video games have achieved a ubiquitous role in the digital society. Not only have they become one of the most popular leisure options, they are also being used for purposes beyond entertainment, such as education, health, and advertising. Their availability in a variety of platforms and formats has also made them more easily accessible. People play using more established platforms (PCs and consoles), but also with their phones and tablets, by themselves or against other players around the world. The global success of the game industry is partly due to localisation, that is, the process of adapting a game technically, linguistically and culturally in order to market and sell it in different territories. However, localisation is often considered a necessary evil by developers and publishers. As game technology advances and the costs of developing triple $A$ titles (the equivalent of cinema blockbusters) soar, localisation has become essential in order to sell as many copies as possible around the world and maximise game companies' return on investment. As such, localisation has become an important process in the game industry, which cannot be overlooked by developers and publishers if they want to achieve global success.

Game technology has advanced over the years, introducing new challenges to the localisation of the medium. The inclusion of dialogues with audio, for example, brought audiovisual translation (AVT) practices, such as dubbing and subtitling, into game localisation (Mangiron \& O'Hagan, 2006). We have come a long way since the early days, when translation of Japanese games was done by developers and contained many errors that in equal parts amused and puzzled Western players. However, localisation practices have not evolved as fast as one would expect, and academic interest in game localisation has been slow to develop. The first publications on the topic were published in the late 1990s and early 2000s (Mangiron, 2017; O'Hagan \& Mangiron, 2013), but there are still several key or burning issues in game localisation, from an industry and/or an academic perspective, which merit further investigation. This paper presents a number of issues that are likely to feature prominently in game localisation research in the near future. These include the position of game localisation within translation studies (TS); its relationship with other types of translation, in particular AVT; game accessibility; reception studies; translation quality; collaborative translation; the use of technology, and translator training.

\section{Game localisation within translation studies}

Video games as an area of study has been tackled by several disciplines, such as computer studies, culture studies, psychology, and game studies, a discipline which started in 2001 with the launch of an academic journal specifically devoted to the study of games (Aarseth, 2001). Academic interest in games from a translation studies perspective initially started at a relatively low level with a few contributions appearing in the early and mid-2000s (Bernal-Merino, 2006; Mangiron \& O'Hagan, 2006; Ortinau, 2004; Scholand, 2002). Related research started to gain impetus in the early 2010s, with the publication of two monographs in English on the subject (Bernal-Merino, 2014; O'Hagan 
\& Mangiron, 2013), followed by three monographs in Spanish a few years later (Granell, Mangiron \& Vidal, 2016; Méndez \& Calvo-Ferrer, 2018; Muñoz-Sánchez, 2017). Although there is now a significant amount of published literature on game localisation, research to date has mainly focused on the description of its main features and the analysis of different localisation models and processes. There are also a handful of studies focusing on various aspects, such as translation strategies (Fernández-Costales, 2012; Mangiron \& O'Hagan, 2006), cultural adaptation (Di Marco, 2007; Edwards, 2011, 2012; Mangiron, 2012c, 2016b) and the translation of humour, to name but a few (Mangiron, 2010; Lepre, 2014).

However, little research has been carried out from an ontological perspective, to build a solid theoretical foundation and methodology for this genre of translation. In fact, the same issue applies to game studies, where an ontological debate to establish what a game is and how to study it (Bogost, 2009) has in turn impacted on the ontology of game localisation. There is also an ongoing discussion regarding the terminology for describing this type of translation, which is often referred to as (video) game localisation and (video) game translation. In her pioneering monograph, industry expert Chandler (2005) uses game localisation to consider not only the act of translation, but also other processes, including the adaptation of graphics, and legal and marketing processes. Bernal-Merino $(2006,2014)$, considers translation the most adequate term when referring to the language transfer that takes place within the broader localisation process. He also states that the term localisation is appropriate within the industry, although it would be advisable to use the terms linguistic localisation or cultural localisation when referring to language translation (2006). O'Hagan and Mangiron (2013) discuss different terminological options, highlighting the more widespread academic debate as to whether localisation encompasses translation, as claimed by the industry, or whether translation is a broader umbrella concept that includes localisation, a view that is shared at an abstract level by the authors (O'Hagan \& Mangiron, 2013). They finally opt for the term game localisation to reflect industry practice, while using game translation interchangeably when referring to the textual operations performed by translators. Ranford (2017) also reflects on the most appropriate term arguing that game localisation implies a reductionist approach to this type of translation, because it presents video games as products, heavily adaptable to fit user needs, and not as an art form. He concludes by opting for the term video game translation, in order to "affirm that videogames are worth the range of debate and analysis afforded to other media in TS [translation studies]" (Ranford, 2017, p. 145). I would argue that game localisation is not a narrow term and by implication it encompasses the range of debate devoted to other media in translation studies. To sum up, the term game localisation and its variants seem to be consolidating in academic literature,' possibly to reflect industry practice, although further research and debate about the ontological nature of this type of translation, its scope, and object of study are still necessary.

Furthermore, the positioning of game localisation within the wider translation studies framework is still unclear. It has been considered by some scholars as a hybrid type of translation (Munday 2008; O'Hagan \& Mangiron, 2013; Remael, 2010), because it combines features of other translation genres, 
mainly software localisation and AVT, but also literary and technical translation. Video games contain language, messages, and instructions to the user similar to those found in a software programme. Their translation is subject to the same constraints as software localisation, such as working with unfinished and unstable text, or without access to the original game, known as blind localisation (Dietz, 2006). Games also frequently contain dialogues and cinematic scenes, and their script can be dubbed, subtitled, or both. In addition, some games - particularly role-playing games (RPG) and adventure games - contain narrative and literary passages, which need to be translated while preserving the literary and poetic register. There are even games that are fully written in rhyme, such as Ubisoft's Child of Light (2014). Other games require translators to carry out a thorough investigation on the functionality and terminology of mechanical technology. As an example, a translator working on the Microsoft Flight Simulator series (1986-2014) would require a similar level of understanding as a technical translator working on a piece about real planes. Therefore, a game translator has to deal with many different game genres and text types. This requires different skills, such as documentation and terminological search; knowledge of the main features and constraints of dubbing and subtitling, and creativity, in order to provide attractive names for items - such as weapons - in their target language and to translate the numerous play-on-words and rhymes that often populate video games.

However, despite the fact that there is now an important amount of literature on game localisation, there are still not enough descriptive case studies allowing researchers to establish regularities and tendencies about issues such as translation strategies, the translation of cultural references, and the translation of humour. In addition, there is little research available in areas such as terminology in game localisation (except Zhang, 2014), corpus studies, and sociological and ideological issues, including censorship (with the exception of Zhang, 2012 and Mandiberg, 2018). The concept of agency and the active and creative role granted to game translators in comparison to translators working in other disciplines is another issue that has received a certain amount of academic attention (Bernal-Merino, 2008b; Gaballo, 2012; laia, 2016; Mangiron \& O'Hagan, 2006; Zhang, 2016), but has not been analysed in depth. Studies analysing the game localisation process from the participants' perspective, and in particular, the translator's perspective, can shed light on the role of the game translator, the creative processes associated with their work, their decision-making process, and their working conditions.

Finally, another burning issue in this area concerns research methodology, which has largely been overlooked to date. Obtaining materials from games and analysing them is complex and timeconsuming, due to their interactive and non-linear nature. Scholars either need to spend time playing the game and taking screen captures or using video walkthroughs recorded and uploaded by other players to viewing platforms such as YouTube to access the game content. In addition, as mentioned in section 5 below, there are few experimental reception studies related to players' experience (cf. O'Hagan 2009, 2016). Undoubtedly, the study of research methodology in game localisation is likely to feature more prominently in the future, in order to define the most appropriate and effective methods to analyse games from the four main paradigms for research 
in translation studies, as proposed by Saldanha and O'Brien (2013): product-oriented, processoriented, participant-oriented, and context-oriented research.

\section{Game localisation and audiovisual translation}

As video games are interactive, audiovisual, multimedia, and multimodal texts, the relationship between game localisation and AVT also merits special attention. It should be highlighted that although research and training in game localisation have been embraced as part of AVT studies, translation practices differ considerably in both industries. In game localisation translation is frequently implemented while the game is being developed. Translators working with the script of a game usually do not have access to the original game, an important source for visual context. Therefore, translators may not know whether they are required to adjust their translations to match the lip movements of the original character or not. Such issues can be overcome by providing screen captures or contextual information about the scene. It would also be helpful to provide information in the game script about how characters speak, as is the case for dubbing for television and cinema. It would be particularly useful to clearly indicate all close-ups, so that translators are aware of the need to take lip-synch into consideration. Some Triple A games, such as Mass Effect 2 (2010), use Al-driven facial modelling technology to match the facial animation to the audio (O'Hagan \& Mangiron, 2013). Industry professionals Black and Crosignani (2014) propose the use of facial video capture when actors are recording the lines for the original version. These captures can then be used to generate 3D models which serve as reference material for translators and enable movie-quality dubbing in Triple A games. However, while this approach is being used more frequently in the industry, it is still not widely adopted. Therefore, the issue of dubbing in games and how to bring this process closer to dubbing practices in other AVT areas remains largely unexplored. In addition, terminological variation is present in this case, as the dubbing of games is referred to in the industry as voice-over (e.g., Chandler, 2005 and Chandler \& Deming, 2012) or audio localisation (Bernal-Merino, 2014; O'Hagan \& Mangiron, 2013; Sioli, Minazzi \& Ballista, 2007).

Subtitling in games is another burning issue in game localisation. Subtitling standards applied in other media, such as television, DVD, and cinema, are often not applied in games. It is not uncommon to find one-line subtitles with 72 characters or more, small fonts, colour clashes between the subtitle and the background, bad segmentation, and lack of synchrony between the audio and the subtitle, to name but a few of the current issues (Mangiron, 2012a). This can be due partially to technical considerations, as on occasion the engine of the game projects the subtitles onto the image automatically. It can also be due to the fact that developers view subtitles as in-game text and are unaware of the subtitling standards applied in other industries. In addition, there are currently no examples of subtitling for the deaf and hard of hearing (SDH) in games, and some games do not contain intralingual subtitles or subtitles for all elements containing audio. This poses an accessibility barrier for deaf and hard of hearing players, 
as explored in more detail in the next section. It should also be highlighted that for console games, game companies demand that intralingual subtitles are transcribed verbatim. This means that there can be no reduction applied to subtitles, and some players may not have enough time to read them. If we take into account that players often have to perform other tasks within a game while reading subtitles - such as fighting or driving a car - the lack of condensation may hinder the gaming experience, as players may miss some information or lose focus from the task they are performing.

Regarding the use of tools, game translators do not work with subtitling programmes. They work instead with Microsoft Excel files or translation memories, so the translation process for subtitles does not really differ from the translation of other types of assets present in a game. In addition, game translators may not have information about time codes or shot changes. Therefore, the way subtitling is handled for a game is quite different to the way subtitling is done for other AVT products. More research is needed on current subtitling practices in order to develop guidelines or a standard for game subtitling that considers the nature of the medium and its interactivity. To conclude this section, it should be stressed that collaboration between industry and academia is essential to improve dubbing and subtitling practices in games. There is also a pressing need to make developers and publishers aware of the importance of providing good quality dubbed and subtitled games to their audience, as this is likely to improve the gameplay experience and, in turn, the reception and sales of their games in target territories.

\section{Game accessibility}

Media accessibility as a topic of study has been embraced by AVT scholars and is one of the more vibrant areas of academic interest within the field, particularly audio description (AD) for people with sight loss and SDH. Game accessibility has also received attention from a game design perspective by a group of scholars and game designers who are members of the International Game Developers' Game Accessibility Special Interest Group, who produced a number of game accessibility guidelines (Game accessibility guidelines, n.d.). However, accessibility relating to gaming remains an overlooked area in translation studies. The few exceptions include contributions by Mangiron (2011, 2012a, 2012b, 2016a), O'Hagan and Mangiron (2013), Fernández-Costales (2014), and Mangiron and Zhang (2016). As mentioned previously, not all games contain intralingual subtitles and not all audio elements in a game are subtitled. For example, sound effects, which are important for gameplay in some genres - such as shooters and horror games - are not available to users with hearing loss if they are not provided via text. The ad-hoc subtitling practices applied in games, the lack of subtitling condensation, and the fact that there is often no method for character identification can present an accessibility barrier to deaf and hard of hearing players (Mangiron, 2012a, 2016a). 
Sign language is another issue in gaming that requires attention. In general, signing is not used in video games, although there is a recent virtual reality game, Moss (2018), the main character of which is a mouse who speaks using American Sign Language. This one game is a positive step towards raising awareness amongst hearing players and also towards fostering the inclusion of users with hearing loss in the gaming community. It will be interesting to see if and how this game is localised into other languages, as sign language varies between communities and it could imply redesigning the animation in order to comply with the sign language of the target communities.

In relation to blind players, accessibility becomes an even more complex issue, due to the visual and interactive nature of the game medium. Players are not only required to understand what is happening on the screen, they are also required to respond to the input provided by the game by taking an action. Currently mainstream commercial video games do not provide $A D$, which means that players with sight loss must play games with the help of sighted users or play versions of games that have been adapted for them with modifications (called mods) or patches. Blind players can play games that have been specifically designed for them, such as audio games, which are sound-based and contain no images, or games that have been designed both for sighted and unsighted players, known as $3 D$ video-less games. Available for mobile phones and tablets, video-less games are designed to provide an innovative and immersive experience to both sighted and unsighted players by using audio only in order to cause suspense and fear (Mangiron \& Zhang, 2016), although they are still few in number. Providing $A D$ for the visual elements of games, as well as including text-to-speech technology and facilitating the use of voice commands to interact with the game, would contribute to enhancing the access of players with sight loss to games. Such technology is already available, so it would be a matter of making developers and publishers aware of the need for improving accessibility practices in games. This would be beneficial for all players and, in turn, may result in more sales.

\section{Reception studies}

Reception studies is an area closely related to AVT transfer modes and game accessibility that can be considered another of the burning issues faced by game localisation researchers. Game localisation is a functional type of translation (e.g., Bernal-Merino, 2014; Di Marco, 2007; Fernández-Costales, 2012; Mangiron \& O'Hagan, 2006;), which aims to provide a similar gameplay experience to players of target versions, so they can enjoy the game like the players of the original version. It is therefore a type of user-centered translation (Suojanen, Koskinen \& Tuominen, 2014). In game localisation the emphasis is placed on the user and how to adapt the text to their needs and expectations in order to facilitate the commercial success by using localisation as part of the marketing strategy. The source text can be subject to an array of changes, not only affecting the text, but also the visual elements of the game, such as character design, the story line, game mechanics or the soundtrack, to name but a few (O'Hagan \& Mangiron, 2013). Developers and publishers expect translators to produce target versions that are as good as originals 
in order to lead players to believe that the game has been designed specifically for them. This emphasis on the user and their experience has been pointed out by authors such as Díaz Montón (2010), who uses the expression emotional localisation to refer to attempts to facilitate players' immersion in the game. O'Hagan uses the expression emotion engineering (2010, 2016; O'Hagan \& Mangiron, 2013) to highlight the need to understand players' emotional experience and replicate it for target players. Lepre (2014) uses the term ludological localisation - from ludology or the study of games - to emphasize the importance of reproducing the gameplay experience of the original version for target players, even if this means redesigning the visual aspects or the story line.

Nevertheless, despite the fact that one of the main tenets of game localisation - both from a theoretical and practical perspective - is that localised versions should provide players with a similar gameplay experience to those playing the original version, no studies have proven whether this is actually the case. Reception studies focusing on players' experience (PX) of both original and target players are few, due to the complexities associated with their design, obtaining subjects, and analysing data. O'Hagan $(2009,2016)$ has pioneered the application of experimental methodologies in game localisation research in order to study PX by means of recording the player trajectory, hand movements and utterances (2009), as well as using biometric data (eye tracking, heart rate, and galvanic skin response measurements) to obtain more objective data about PX and the reception of humour (2016). O'Hagan (2009; 2016) also carried out post-task interviews to obtain qualitative data and triangulate it with the biometric data. A pilot experimental study (Mangiron, 2016) was also carried out to assess the reception of game subtitles in video games using eye-tracking technology and questionnaires, with both hearing and deaf players. However, further investigation into the affective dimension of game localisation and its emphasis on the user is necessary in order to shed more light on game localisation theory and practice. Large scale cross-cultural experimental reception studies involving interdisciplinary teams of researchers from fields such as game design, psychology, and translation studies, can help obtain data about PX of both original and target users, which could in turn inform game design and localisation strategies (Mangiron, 2018).

In addition to experimental studies, a number of reception studies using questionnaires and focusing on players' views about localised games and their language preferences have been carried out by Geurts (2015) in the Dutch context, Fernández-Costales (2016) in the Spanish context, and Ellefsen (2016) in French-speaking territories. González-Barrionuevo (2017) provides a broader study of the reception of creative language in video games with users from different languages. Undoubtedly, reception studies will feature more predominantly in future research into game localisation, as little is known about players' preferences, such as their preferred AVT mode for localised games, or their preferred localisation strategies for specific game genres or text types. To date, the localisation industry has largely tended towards adaptation and domestication, particularly when localising Japanese games, but without really asking players whether they prefer such strategies or if they would rather enjoy playing games that preserve some of their original flavour. 
In the case of languages spoken in different territories, another issue that deserves attention is the preferred language variety for playing, as in Ellefsen's (2016) study on French-speaking locales. In the case of Spanish, for example, there are numerous regional variations, but the game industry tends to opt for a Castilian Spanish version only, a Castilian Spanish version for Spain and a Latin American Spanish version for the remaining territories, which tends to be based on Mexican Spanish, or a neutral Spanish version for all territories. However, regional varieties of Spanish differ greatly, in particular when it comes to colloquial language and slang and players may not be satisfied with the available version. Studies on users' preferences based on questionnaires can be triangulated with experimental reception tests to obtain data about users' linguistic preferences when playing games. This, in turn, would help the game industry to fine-tune their localisation approaches and strategies for different game types and territories.

\section{Quality and collaborative translation}

Quality and how to measure it is another burning issue for the game localisation industry. Little attention has been devoted by scholars to the quality assessment process in game localisation, despite the fact that detecting translation errors - arising from issues such as the lack of context is crucial to ensuring the quality of localised games. Furthermore, it would be beneficial for the industry to develop quality evaluation models, measures, and methodologies for assessing the quality of localised versions in line with related fields, such as software localisation and machine translation. This issue of quality is closely linked to another relatively recent phenomenon in translation theory and practice: collaborative translation in the form of fan translation and crowdsourcing.

Video game fan translation practices, which developed at the end of the 1990s, are known as romhacking, because in order to embed the translation into the original code, fan translators need to hack the original game to perform a reverse engineering process (MuñozSánchez, 2007). Originally, the main motivations behind fan translations were to localise Japanese games for English speaking players, or to improve the quality of existing translations via mods or patches because fans were either not satisfied with the quality of official translations or desired uncensored access to the original version. Interestingly, fan translators often embark on the localisation of a game because they feel that they are not able to experience the game in a similar way to the original players. Thus, fan translations of Japanese games tend to be more literal and more exoticising than official translations, which are sometimes criticised by fans for being too local and for removing traces of the original Japanese culture. This seems paradoxical, as the main objective of game localisation is to provide target players with a similar PX, and that is the reason why games tend to be heavily adapted. Therefore, further research is needed in order to find out more about players' reception of fan-localised versions versus the officially localised versions of games. This in turn could help developers and publishers to tailor 
localisation strategies, by taking into account the audience, genre, theme and cultural content of a game. In addition, analysing players' and fans' reactions to localised games on specialised websites and forums, as well as in social media, can provide interesting data about localisation approaches and their perception by players. Interviews with fan translators can also provide information about their motivations as well as their working and decision-making processes.

Crowdsourcing is a more recent phenomenon in game localisation, both from an academic and an industry perspective. Unlike fan translation, which originates from the fans and with no expectation of financial gain, crowdsourcing often originates from a call by developers for fans to translate a game, because the latter are usually passionate and knowledgeable about the games. It is often used by independent developers who have limited budgets for their projects and cannot afford professional localisation. Therefore, this type of localisation is in direct competition with professional localisation. It should be mentioned that there is also the possibility of employing the services of start-up companies that use crowdsourcing as a business model and provide fast and cheap translations. Translators receive little remuneration for such work but gain experience and status in the translation community if their translations are voted the best ones. Even some established localisation vendors are now offering crowdsourced translation as part of their localisation services to provide fast and cost-effective translation solutions. In the case of minority languages, as developers and publishers do not consider localised versions worth the investment, fan translations may be the only option to bring the game to target players in their own languages.

The quality of fan translations and crowdsourced translations varies greatly, and such translations often contain linguistic errors. This is understandable considering that many of the fans carrying out translations are not translators or language specialists. This poses interesting questions regarding quality. Are there different quality standards for different purposes and different groups of users? Is it better to have access to a fan-translated game even if the quality is not good, than not having the game translated at all? Do players care about the linguistic quality of a game? How does it affect their overall play experience? Is the quality of a game related to its language or is it related to the story and game mechanics? The Japanese RPG Final Fantasy VII (1997) is considered among the best of its kind in the history of video games, but the quality of the early localised versions was harshly criticised. So, what do users really value? Again, reception studies can contribute to answering all these questions.

\section{Technology}

Despite the fact that the video game industry is technologically-driven and has advanced at vertiginous speed, localisation technology has not kept pace. For many developers, Microsoft Excel files are still the preferred format for translation because such files are easy to export and import, even though Excel is not an application specifically designed for translation. Developers who have in- 
house translation departments often do not work with computer-assisted translation (CAT) tools because they tend to perceive their work as a creative process, more similar to literary translation than software localisation. However, a number of developers and specialised game translator vendors use content management systems and CAT tools in order to improve their productivity. There are also localisation management solutions, such as XLOC (www.xloc.com), which have been specifically designed for the game localisation industry. Undoubtedly, the translation of certain text assets, such as system messages - which are usually platform-specific - or the name of weapons, abilities, and objects from games in a saga can benefit from using translation memories and terminology management tools, as they tend to be repeated in different games. In addition, as assets for translation are often distributed among different translators in order to meet tight deadlines, the use of CAT and terminology management tools can also contribute to maintaining consistent translation styles. More research on the different tools and technologies applied to game localisation, how they affect translators' work, and how they can optimise the localisation process is necessary and would be beneficial for the industry.

Another technological issue that is likely to have an effect on game localisation practices is the increasing use of augmented reality (AR) and virtual reality (VR) in games. This will have an impact at a terminological level, with new terms requiring translation into different languages. In addition, in the case of VR there are particular challenges regarding the placement of text, such as the text that appears in the user interface and the subtitles, which is essential to guarantee accessibility for deaf and hard of hearing players.

Finally, a technology-related topic that is increasingly attracting game industry attention is the application of machine translation to game localisation. While machine translation may not work with all kinds of game genres and text assets - especially those that are contain more creative and idiomatic language -, it could work with the more technical text types present in games, such as system messages and tutorials. It may also work on certain game genres which rely more heavily on terminology than on creativity, such as sport games or flight simulator games. As machine translation can help reduce the time and cost of the game localisation process, this area can be expected to attract more interest both from academia and the industry in the coming years.

\section{Training}

Game localisation training is another important issue for the industry and academia. Since 2003 Spain has been one of the countries pioneering the training of game translators, particularly at postgraduate level. The growing demand for game translators in the industry and the popularity of this type of translation among students has resulted in the proliferation of training courses. Due to its hybrid nature, game localisation can be found in the curriculum of Master's degrees in specialised translation, AVT, translation technologies, and multimedia 
translation." A number of authors have looked at the didactics of game translation - such as BernalMerino (2008a), Granell (2011), and O'Hagan and Mangiron (2013) - focusing on issues such as competencies and curriculum design. Vela-Valido (2011) examined the history of game localisation teaching in Spain, and Carreira and Arrés (2014) conducted a survey of courses that include some game translation at undergraduate level, but more research is needed in this area.

One of topics often debated is whether a game translator needs to be a gamer. Most job advertisements looking for localisation specialists (the term often used in the industry) require them to be gamers or at least have some knowledge about video games. However, the author of this paper has met many game translators who were not gamers. Being a gamer is certainly an advantage when translating blind-folded, without access to the original game, as one's intuition can help decide which of the possible translations for a string is the most appropriate. For example, is the string open a button or is it a sign for a shop window? Or if it is a dialogue line, is it addressed to one or more characters? While translators who are gamers may find it easier to identify the most likely function of a given string, non-gamer translators who have received training in game localisation should be able to make educated guesses as well.

The difficulty in obtaining training materials due to the confidential nature of the industry should also be highlighted. Because of this, trainers have to manually transcribe the text from the game or work with open source games which are freely available. One of the pending issues in this area is to establish a fruitful collaboration between industry and academia so that companies can provide trainers with localisable assets of older games. This would also allow for the implementation of smallscale localisation projects which replicate all the steps of a professional localisation project, including quality assessment of the localised game. Collaboration in the form of internships and mentoring programmes can also be beneficial for both parties and is another avenue to explore. More research will be needed to keep up to date with the latest developments in the industry in terms of localisation practices, the use of technology, and the competences and professional profile required for the role. Consideration also needs to be given to the incorporation of such information into the training of future professionals to meet the industry needs.

\section{Conclusions}

Game localisation is a bourgeoning type of translation that is increasingly attracting the attention of scholars due to its hybrid nature. It shares features in common with other types of translation, mainly AVT and software localisation, but also technical and literary translation. Despite the growing interest in this field there are still several burning issues requiring further scholarly attention. As discussed in this paper, these include: the most appropriate term to refer to this type of translation; its positioning within the wider translation studies framework and the methodology most appropriate to carry out research in the field; its relationship with other translation genres, in particular AVT; game accessibility; reception studies; quality assessment; collaborative translation; 
the impact of technology on localisation practices, and translator training. In order to overcome all these issues and keep advancing the field collaboration will be essential, not only among researchers from different disciplines such as translation studies, game studies and psychology, but also between academia and the industry. Numerous exciting challenges lie ahead for researchers willing to overcome these burning issues and bring research and practice in this area to the next level. The game is not over yet.

\section{Biographical note}

Carme Mangiron, PhD, is a lecturer and a member of the research group TransMedia Catalonia at the Universitat Autònoma de Barcelona (UAB). She is also the Programme Director of the MA in Audiovisual Translation at UAB. Carme has extensive experience as a translator, specialising in software and game localisation. Her research interests include game localisation, game accessibility, audiovisual translation and media accessibility. She has published extensively in international journals and participated in several national and international research projects. She is co-author of Game Localization: Translating for the Global Digital Entertainment Industry (O'Hagan and Mangiron, 2013), one of the editors of Fun for All: Translation and Accessibility Practices in Video Games (Mangiron, Orero \& O'Hagan, 2014) and the organizer of the Fun for All: Translation and Accessibility in Video Games Conference, which started in 2010 and runs every two years.

\section{References}

Aarseth, E. (2001). Computer game studies, year one. Game Studies, 1(1). Retrieved from http://www.gamestudies.org/0101/editorial.html

Bernal-Merino, M. A. (2006). On the translation of video games. The Journal of Specialised Translation, 6, 22-36. Retrieved from http://www.jostrans.org/issue06/art bernal.php

Bernal-Merino, M. A. (2008a). Training translators for the video game industry. In J. Díaz-Cintas (Ed.), The didactics of audiovisual translation (pp. 141-155). Amsterdam \& Philadelphia, PA: John Benjamins.

Bernal-Merino, M. A. (2008b). Creativity in the translation of video games. Quaderns de Filologia. Estudis literaris XIII, 71-84. Retrieved from http://roderic.uv.es/bitstream/handle/10550/31595/57.pdf?sequence=1

Bernal-Merino, M. A. (2014). Translation and localisation in video games. Making entertainment software global. New York, NY: Routledge.

Black, B. \& Crosignani, S. (2014). Employing video recording techniques in localization. Multilingual, June 2014, 31-33.

Bogost, I. (2009, September 3). Videogames are a mess: My DiGRA 2009 keynote, on videogames and ontology. 
Carreira, O. \& Arrés, E. (2014). Video game localisation training on offer in Spanish universities at undergraduate level. In C. Mangiron, P. Orero \& M. O'Hagan (Eds.), Fun for all: Translation and accessibility practices in video games (pp. 243-268). Bern: Peter Lang.

Chandler, H. M. (2005). The Game localization handbook. Hingham, MA: Charles River Media.

Chandler, H. M. \& Deming, S. O. (2012). The game localization handbook (2nd ed.). Sudbury, MA: Jones \& Bartlett Learning.

Child of Light [Computer software]. (2014). Montréal: Ubisoft.

Díaz Montón, D. (2010). Emotional localisation: connecting with the player. [PowerPoint Slides] Retrieved from https://www.slideshare.net/maloria/emotional-localization

Dietz, F. (2006). Issues in localizing computer games. In K. J. Dunne (Ed.), Perspectives in localization (pp. 121-134). Amsterdam \& Philadelphia, PA: John Benjamins.

Di Marco, F. (2007). Cultural localization: Orientation and disorientation in Japanese video games. Revista Tradumàtica, 5, 1-8. Retrieved from

http://www.fti.uab.es/tradumatica/revista/num5/articles/06/06.pdf

Final Fantasy VII [Computer software]. (2014). Tokyo: Square.

Edwards, K. (2011). Culturalization: The geopolitical and cultural dimension of game content. TRANS. Revista de Traductología, 15, 19-28. Retrieved from

http://www.trans.uma.es/pdf/Trans 15/19-28.pdf

Edwards, K. (2012). Beyond localization: An overview of game culturalization. In C. Mangiron, P. Orero \& M. O'Hagan (Eds.), Fun for all: Translation and accessibility practices in video games (pp. 287-303). Bern: Peter Lang.

Ellefsen, U. (2016). Harnessing the roar of the crowd: A quantitative study of language preferences

in video games of French players of the Northern Hemisphere (Unpublished master's dissertation). University of Roehampton, London.

Fernández-Costales, A. (2012). Exploring translation strategies in video game localization. MonTI: monografías de traducción e interpretación, 4, 385-408. Retrieved from https://rua.ua.es/dspace/bitstream/10045/26956/1/MonTI 04 17.pdf

Fernández-Costales, A. (2014). Translating fun for all: promoting accessibility in video games. In C. Mangiron, P. Orero \& M. O'Hagan (Eds.), Fun for all: translation and accessibility practices in video games (pp. 45-66). Bern: Peter Lang.

Fernández Costales, A. (2016). Analyzing player's perception on the translation of video games.

In I. R. Smith, A. Esser \& M. A. Bernal-Merino (Eds.), Media across borders: Localizing TV, film, and video games (pp. 183-201). New York, NY: Routledge.

Gaballo, V. (2012). Exploring the boundaries of transcreation in specialized translation. ESP Across

Cultures, 9, 95-113. Retrieved from

https://edipuglia.it/wp-content/uploads/ESP\%202012/Gaballo.pdf

Game accessibility guidelines (n.d.). Retrieved from http://gameaccessibilityguidelines.com/

Geurts, F. (2015). What do you want to play? The desirability of video game translations from English into Dutch according to Dutch gamers and non-gamers (Unpublished master's dissertation). University of Leiden, The Netherlands. Retrieved from 
https://openaccess.leidenuniv.nl/bitstream/handle/1887/34704/Complete\%20thesis\%202 015-07-20\%20final.pdf?sequence $=1$

González-Barrionuevo, F. (2017). La creatividad en la localización de videojuegos. Estudio de caso de

"Pokémon Sol y Luna" [Creativity in game localisation. Case study of "Pokémon Sun and Moon"] (Unpublished master's dissertation). Universitat Autònoma de Barcelona

Granell, X. (2011). Teaching video game localization in audiovisual translation courses at University.

The Journal of Specialised Translation, 16, 185-202. Retrieved from http://www.jostrans.org/issue16/art granell.pdf

Granell, X.; Mangiron, C. \& Vidal, N. (2016). La traducción de videojuegos [Translation of video games]. Sevilla: Bienza.

laia, P. (2016). Creativity and readability in game localisation. A case study on "Ni No Kuni". Lingue e Linguaggi, 17, 121-132. Retrieved from

http://siba-ese.unisalento.it/index.php/linguelinguaggi/article/view/15641/13976

Lepre, O. (2014). Divided by language, united by gameplay: An example of ludological game localization. In C. Mangiron, P. Orero \& M. O'Hagan (Eds), Fun for all: Translation and accessibility practices in video games (pp. 111-128). Bern: Peter Lang.

Mandiberg, S. (2018). Fallacies of game localization: Censorship and \#TorrentialDownpour.

The Journal of Internationalization and Localization, 4, 162-182.

Mangiron, C. (2010). The importance of not being earnest: Translating humour in video games.

In D. Chiaro (Ed.), Translation, humour and the media (pp. 89-107). London: Continuum.

Mangiron, C. (2011). Accesibilidad a los videojuegos: estado actual y perspectivas futuras. [Video game accessibility: current situation and future perspectives]. TRANS. Revista de Traductología, 15, 53-67. Retrieved from http://www.trans.uma.es/pdf/Trans M

Mangiron, C. (2012a). Subtitling in game localization: A descriptive study. Perspectives: Studies in Translatology , 21(1), 42-56.

Mangiron, C. (2012b). Exploring new paths towards game accessibility. In A. Remael, P. Orero \& M. Carroll (Eds.), Audiovisual translation and media accessibility at the crossroads. Media for all 3 (pp. 43-59). Amsterdam: Rodopi.

Mangiron, C. (2012c). The localisation of Japanese video games: Striking the right balance. JIAL: The Journal of Internationalisation and Localisation, II, 1-21. Retrieved from

https://benjamins.com/\#catalog/journals/jial.2.01man/fulltext

Mangiron, C. (2016a). Reception of game subtitles: An empirical study. The Translator, 22(1), 72-93.

Mangiron, C. (2016b). Games without borders: The cultural dimension of game localization.

Hermeneus: Revista de Traducción e Interpretación, 18, 187-208. Retrieved from

http://www5.uva.es/hermeneus/wp-content/uploads/arti06 18.pdf

Mangiron, C. (2017). Research in game localisation: An overview. The Journal of Internationalization and Localization, 4(2), 74-99.

Mangiron, C. (2018). Reception studies in game localisation: Taking stock. In E. Di Giovanni \& Y. Gambier. Reception studies and audiovisual translation (pp. 277-296). Amsterdam \& Philadelphia, PA: John Benjamins. 
Mangiron, C. \& O'Hagan, M. (2006). Video Games Localisation: Unleashing Imagination with Restricted Translation. The Journal of Specialised Translation, 6, 10-21. Retrieved from https://www.jostrans.org/issue06/art ohagan.pdf

Mangiron, C. \& Zhang, X. (2016). Game accessibility for the blind: Current overview and the potential application of audio description as the way forward. In A. Matamala \& P. Orero (Eds.), Researching audio description new approaches (pp. 75-95). London: Palgrave McMillan.

Mass Effect 2 [Computer software] (2010). Edmonton: BioWare.

Méndez, R. \& Calvo-Ferrer, J. R. (2018). Videojuegos y [para]traducción: aproximación a la práctica localizadora. [Video games and [para]translation: aproximation to translation practice]. Granada: Comares.

Microsoft Flight Simulator [Computer software]. (1986-2014). Redmont: Microsoft.

Moss [Computer software] (2010). Seattle: Polyarc.

Munday, J. (2008). Introducing translation studies: Theories and applications. London \& New York, NY: Routledge.

Muñoz-Sánchez, P. (2007). Romhacking: localización de videojuegos clásicos en un contexto de aficionados [Romhacking: classic game localisation in a fan context]. Revista Tradumàtica, 5: Localització de videojocs [Game localisation], 1-9. Retrieved from

http://www.fti.uab.es/tradumatica/revista/num5/articles/07/07.pdf

Muñoz-Sánchez, P. (2017). Localización de videojuegos. Madrid: Síntesis.

O'Hagan, M. (2009). Towards a cross-cultural game design: An explorative study in understanding the player experience of a localised Japanese video game. The Journal of Specialised Translation, 11, 211-233. Retrieved from http://www.jostrans.org/issue11/art ohagan.pdf

O'Hagan, M. (2010, December). Engineering emotion? - Translators' new role in serving the digital entertainment industry. Keynote lecture delivered at the I International Conference on Video Game and Virtual Worlds Translation and Accessibility, Universitat Autónoma de Barcelona.

O'Hagan, M. (2016). Game localisation as emotion engineering: Methodological exploration. In M. O'Hagan \& Q. Zhang (Eds.), Conflict and Communication: A changing Asia in a globalising world (pp. 81-102). New York, NY: Nova.

O'Hagan, M., \& Mangiron, C. (2013). Game localisation: Translating for the global digital age. Amsterdam \& Philadelphia, PA: John Benjamins.

Ortinau, E. (2004). Zur lokalisierung von computerspielen: Patrizier II und command \& conquer 1-3 als exemplarische fälle [Localization of computer games: Patrizier II and cCmmand \& conquer 1-3 as exemplary cases]. Trier: WVT Wissenschaftlicher Verlag.

Ranford, A. (2017). Targeted translation. How game translations are used to meet market expectations. The Journal of Internationalization of Localization, 4(2), 141-161.

Remael, A. (2010). Audiovisual translation. In Y. Gambier \& L. van Doorslaer (Eds.), Handbook of translation studies, Volume 1 (pp. 12-17). Amsterdam \& Philadelphia: John Benjamins.

Saldanha, G. \& O'Brien, S. (2013). Research methodologies in translation studies. London: Routledge.

Scholand, M. (2002). Localización de videojuegos [Game Localisation]. Revista Tradumàtica, 1, 1-9. Retrieved from 


\section{http://www.fti.uab.es/tradumatica/revista/articles/mscholand/mscholand.PDF}

Sioli, F., Minazzi, F., \& Ballista, A. (2007). Audio localization for language service providers. Multilingual Localization: Getting Started Guide, October-November 2007, 18-23. Retrieved from https://multilingual.com/all-articles/?art id=1004

Suojanen, T., Koskinen, K. \& Tuominen, T. (2014). User-centered translation. London \& New York, NY: Routledge.

Vela-Valido, J. (2011). La formación académica de los traductores de videojuegos en España: Retos y propuestas para docentes e investigadores [Academic training of video game translators in Spain: Challenges and proposals]. TRANS. Revista de Traductología, 15, 89-102. Retrieved from http://www.trans.uma.es/pdf/Trans 15/89-102.pdf

Zhang, X. (2012). Censorship and digital games localization in China. Meta: Journal des Traducteurs, 57, 338-350. Retrieved from

\section{https://www.erudit.org/revue/meta/2012/v57/n2/1013949ar.pdf}

Zhang, X. (2014). Terminology management in video games localisation. In C. Mangiron, P. Orero \& M. O'Hagan (Eds.), Fun for all: Translation and accessibility practices in video games (pp. 197-215). Bern: Peter Lang.

Zhang, X. (2016). Key actors in the network of game localisation in China (Unpublished doctoral dissertation). University of Vienna, Austria.

\footnotetext{
' A quick search in Google Scholar at the time of writing this article reveals that the predominant term is game localization, with US English spelling, with 677 results, and 322 results for game localisation, its UK English equivalent. "Game translation", on the other hand, appears in 345 results.

"For example, in the Spanish context, there is the MA in Specialised Translation by the Universitat de Vic (Barcelona); the MA in Audiovisual Translation and the MA in Translation Technologies at the Universitat Autònoma de Barcelona; the MA in Multimedia Translation at the Universidade de Vigo, the MA in Translation and New Technologies at the Universidad Internacional Menéndez Pelayo and the Instituto Superior de Estudios Lingüísticos (ISTRAD) and the MA in Audiovisual Translation from the Universidad de Cádiz and ISTRAD. In the British context, the University of Roehampton offers game localisation in the Postgraduate courses in Specialised Translation and Audiovisual Translation, and the University of Bristol in the MA in Chinese-English Translation. University College London also offers a three-month course on game localisation. In the Italian context, the Università di Bologna also offers game localisation in their MA on Specialised Translation.
} 